\title{
Loving, but not Loved: The New Kypris Song in the Context of Sappho's Poetry ${ }^{1}$
}

\author{
Renate Schlesier
}

Since the first notification of a papyrus with two new Sappho poems by Dirk Obbink on the world-wide-web in January 2014, and especially since its publication in Zeitschrift für Papyrologie und Epigraphik some months later together with four other papyri (all poems in 'Sapphic stanzas' and belonging to Book 1 of the Alexandrian edition of Sappho), there has already been much debate on the two new incomplete poems. This debate has concentrated on the so-called 'Brothers Poem' of which the last five stanzas are almost complete; less has been said on the second poem, the 'Kypris Poem', of which the first four stanzas (when joined with another papyrus) remain, unfortunately, poorly preserved. In what follows I shall concentrate on this latter poem, taking into account in particular the editio princeps and the reconstructions of and comments on the text by Martin West and Franco Ferrari which were published in subsequent volumes of ZPE, as well as Dirk Obbink's new restorations published in this volume. ${ }^{2}$ Furthermore, I shall attempt to contextualize the poem, mainly with regard to Sappho's hitherto extant work.

1 I am very grateful to the editors for giving me the opportunity to publish these notes in this volume connected with the Sappho conference organized by Toni Bierl in Kaiseraugst/Basel in June 2014, and for their helpful comments on a previous version of my paper; to Dirk Obbink who shared long hours of fruitful discussion on the new papyrus with me when we met in Warsaw, Basel, and Oxford in Summer and Fall 2014 and February 2015, prolonged by extensive e-mail exchange; and to numerous others among my friends, colleagues, and students, with whom I had the chance to speak about the two new Sappho poems during the first year after their publication.

2 Obbink (2014b), West (2014), Ferrari (2014), Obbink (ch. 1, this volume). See also Burris, Fish, and Obbink (2014) and Obbink (2015b). Cf. Benelli (2015). On the Kypris song, see furthermore the contributions by Bierl (ch. 15), Boehringer and Calame, and Rayor to this volume.

(C) RENATE SCHLESIER, 2016 | DOI: 10.1163/9789004314832_019

This is an open access chapter distributed under the terms of the Creative Commons Attribution-

Noncommercial 3.0 Unported (CC-BY-NC 3.0) License. 


\section{Aphrodite and Her Titles in Sappho}

Some preliminary observations are in order, since the new Kypris song is a further testimony of the singularly eminent position occupied by Aphrodite in Sappho's poetry. ${ }^{3}$ In the indirect and direct transmission of her songs, encompassing no more than circa $10 \%$ of her production, Aphrodite is by far the most prominent deity and seems to be typically presented as alter ego of the poetess. This prominence emerges from many poems in several, if not all, books of the Alexandrian edition of her work. ${ }^{4}$ In Sappho's extant poetry, Aphrodite is explicitly mentioned in no less than eighteen fragments, ${ }^{5}$ and is evidently or probably referred to in at least eight or more others. ${ }^{6}$ Thirteen or fourteen of these twenty-six or twenty-eight fragments are addresses to the goddess, and in three of them the goddess addresses the poet by her name, 'Psappho' (while such an address by a deity is completely absent from the extant work of all male archaic poets). ${ }^{7}$ The name 'Aphrodite' itself appears in seven fragments,

3 This conspicuous focus on Aphrodite distinguishes Sappho from all the male poets of the archaic period.

4 Aphrodite is not at all 'virtually missing' outside of Book 1, as Obbink (2015b) 6 asserts. See the exhaustive evidence of verses in several meters documented in nn. $5^{-11}$ below.

5 Aphrodite - under different names and cult titles (see below, nn. 8-11) —in Sappho's poetry: frs. 1, 2, 5, 15, 22, 33, 44, 65, 73a, 86, 90, 96, 102, 112, 133, 134, 140 (and now the new Kypris poem). Here and elsewhere, if not otherwise noted, the numbers of the Sappho fragments correspond to the edition of Voigt (1971), whose Greek text I adopt, while also taking into consideration the editions of Lobel and Page (1955) and Campbell (1982a). On Aphrodite and her titles and epithets in ancient Greek epic see Boedeker (1973) 16-50.

6 Aphrodite, evidently referred to, but without transmitted name: fr. 35, fr. 101 (both are addresses to the goddess), fr. 159; probably: fr. 40 (address pointing to the sacrifice of a white goat), use of notorious epithets: fr. $58.9 \tau \dot{\alpha} \nu$ [ $\pi 0 \lambda v \omega$ ' $v v \mu \circ \nu$ ('the one [fem.] with many names'),

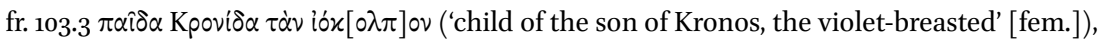

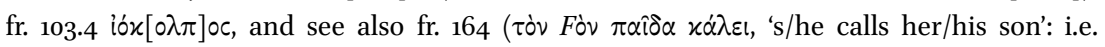
Aphrodite's calling of Eros?). In addition to these eight fragments, two others may also point to Aphrodite: as has often been noted, the goddess is almost certainly referred to in fr. 16 (v. 12 or vv. 13-14), cf. now, with reference to the new papyri, Burris, Fish, and Obbink (2014) 17, West (2014) 2-3, and Obbink (ch. 1, this volume). Furthermore, in fr. 95.9 the emphatic appeal $\mu \dot{\alpha}$

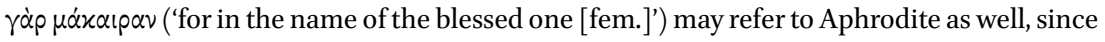
makaira is also the epithet she receives in an address by the poetic persona in fr. 1.13. Cf. fr. 15.1, where the same term seems to be used.

7 'Psappho', addressed by Aphrodite: fr. 1.20, fr. 65.5, fr. 133b. Cf. also a further fragment where the goddess addresses the poetic persona (without mentioning her name) together with Eros: fr. 159. On female personal names in Sappho see Schlesier (2013). On addresses to humans in her poetry see moreover Schlesier (2015), especially with regard to fr. 94, the only other 
though only in two as an address. ${ }^{8}$ Among the cult titles and epithets, 'Kytherea' is used three times (twice as an address). ${ }^{9}$ Yet most of the time, Sappho uses for Aphrodite titles and epithets that emphasize the particularly close connection of the goddess with the island of Cyprus which was certainly one of her eldest and most important cult places in Greek antiquity: Kypris (so far attested four times, including now in the new poem) and Kyprogenea (two or three times), regularly in an address, ${ }^{10}$ as well as 'queen (basilea) on Cyprus'.11

fragment where Sappho is addressed by her name, this time by an (anonymous) human female who seems to have played the role of Aphrodite in the past. Elsewhere in early Greek poetry the mentioning of the author's name is very rare (the speaker never being a deity): Hes. Theog. 22; Alcm. fr. 39.1; Solon fr. 33.1; Thgn. 22.

8 'Aphrodite' in addresses: fr. 1.1 (in vv. 1-2 connected with four epithets: $\pi$ ox $1 \lambda$ ó $\theta$ povoc,

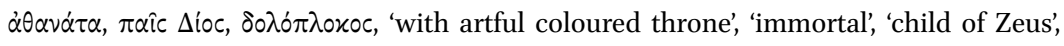
'weaver of cunnings', in v. 4 addressed as $\pi \dot{\tau} \tau v$ l $\alpha$, 'female sovereign', and in v. 13-pointing

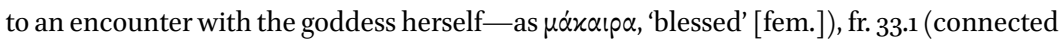

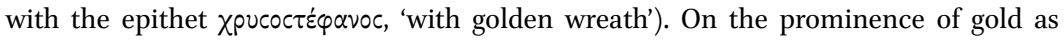
terminological feature in Sappho's poetry, with special regard to Aphrodite and her epic epithet Xpucén ('golden'), see Schlesier (2014b). On the complicated structure of fr. 1 see Schlesier (2011a). On invocations of the goddess in Sappho, in comparison with addresses of other deities: Schlesier (2011b) 16-17. The name Aphrodite also appears in fr. 73a.3, fr. 96.26 , fr. 102.2, fr. 112.5, fr. 133 b (connected to the epithet $\pi \circ \lambda \dot{0} 0 \lambda \beta \circ c$, 'with much bliss'), although she is not addressed in these fragments.

9 'Kytherea' in addresses: frs. 86.3 (a prayer of the poetic persona), 140.1 (an address to the goddess by female chorus members [korai], in the context of the cult of Adonis); cf. fr. goa

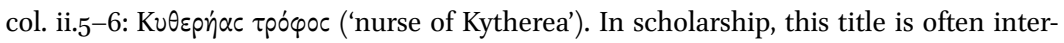
preted as reference to the island of Cythera south of the Peloponnese, which is presented as her destination in Hesiod, Theog. 198 (as explanation of the title 'Kythereia'). However, Morgan (1978) suggests an etymology connected with $\chi \varepsilon \dot{\theta} \theta \omega$ ('to hide', 'to conceal'), something presented as typical of the habitus of the goddess in ancient tradition. Note that Hesiod (Theog. 199) designates Cyprus, not Cythera, as her birth-place and calls her, accordingly, 'Kyprogenea'. See also below, n. 10. On Aphrodite and Cythera see PirenneDelforge (1994) 217-226.

10 'Kypris', hitherto always in addresses: frs. 2.13, 5.18, 15.9, and now in the new Kypris poem, v. 2 (the title possibly also in fr. 16.12, and inc. auct. 42.7). 'Kyprogenea' in addresses: frs.

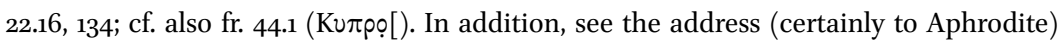
quoted by Strabo 1.2.33 (= fr. 35, transl. Campbell): 'either Cyprus or Paphos or Panormus

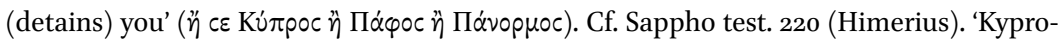
genea' (as invocation): also in Alcaeus fr. 296b.1; cf. Alc. fr. 380 ('Kypris', however, is absent from the extant work of Alcaeus). On Aphrodite and Cyprus see Pirenne-Delforge (1994) 309-369.

11 'On Cyprus queen': fr. 65.6 (Kú $\pi \rho \omega ! \beta[\alpha] c i \lambda[\eta \alpha$ ). However, the gen. Kú $\pi \rho \omega$ ('of Cyprus') would be a possible reading as well, see Voigt ad loc. In the context of this very mutilated 
As a matter of fact, this special relationship of Aphrodite to Cyprus, as expressed in those titles, is a familiar feature of Greek literature since Homer. It is remarkable, however, that her title Kypris, being absent from the Odyssey and only appearing in Book 5 of the Iliad, ${ }^{12}$ is not used as a distinctively local epithet. Instead, it is exclusively connected with a particular episode of the Trojan war, the wounding of the goddess by the Greek warrior Diomedes while she tries to save her mortal son, the Trojan prince Aeneas (thereafter successfully saved by Apollo) from Diomedes' attack. Strikingly, this action makes her the target of accusations by both Athena and Hera, the main divine allies of the Greeks, who slander her to Zeus; these are paralleled by accusations against Diomedes for his attack on the goddess first on the part of Apollo (to Ares) and then of Ares (to Zeus).

In this context, two elements deserve special attention: first, the fact that both male gods describe Diomedes' wounding of Kypris by an identical for-

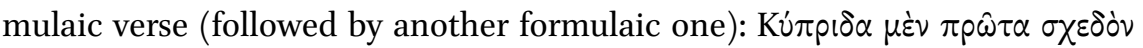

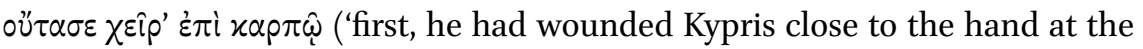
wrist'), ${ }^{13}$ using an expression that often designates, in the Iliad, the targeting of a mortal warrior at this particularly sensitive body part, but is also associated with dancing in a chorus and becomes, beginning with the Odyssey, a locution for the gesture with which a man seizes a woman, ${ }^{14}$ especially in connection with marriage. In other words, by this locution Kypris is in Homer emblematically associated with dangerous fighting and with ambivalent-painful as well as lustful_-relationships between the sexes, as well as between a mortal man and a goddess. Second, Athena, alluding disparagingly to the story of

poem on papyrus Aphrodite seems to declare her love for the poetess, addressing her by

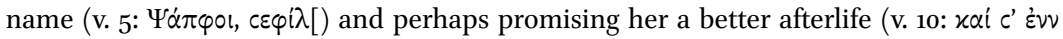
'A $\chi \dot{\varepsilon} \rho[0 v \tau$, 'also you on the Acheron'). On the appeal to Aphrodite in Sappho's claims to immortality for her poetic persona see Schlesier (2011b), cf. Boedeker (1979). Note that in the first poem (the so-called 'Brothers Poem') of the new papyrus, 'queen' (basilea) Hera (v. 10[6]) is presented as recommended addressee of a prayer, though 'queen' as cult title of the Lesbian Hera is not otherwise attested.

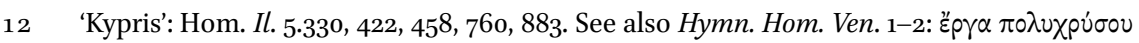

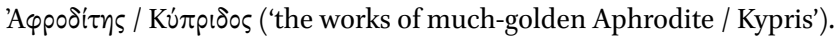

13 Il. 5.458 and 883.

14 The first instance pointing to this terminological significance of the gesture $\chi \varepsilon \hat{\imath} \rho^{\prime}$ ' $\pi \mathrm{i}$ x $\alpha \rho \pi \hat{\omega}$ is $O d$. 18.258. See later the depictions of bride and bridegroom on Attic vase paintings. Elsewhere in epic, this gesture is also connected with dancing: Il. 18.594 (Ariadne's chorus of girls and young men in Crete, on the shield of Achilles); cf. Hymn. Hom. Ap. 196 (dances of goddesses, including Aphrodite). 
Helen, pretends that Kypris' wounding would rather be self-inflicted: $\hat{\eta} \mu \alpha \dot{\lambda} \alpha \alpha \delta^{\prime}$

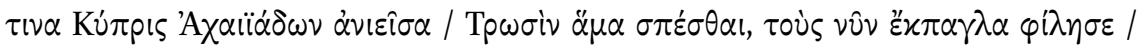

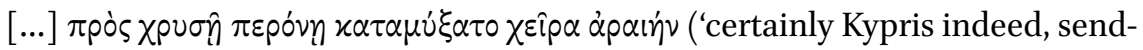
ing up one of the women of Achaea / to be in company with the Trojans, whom she now exceedingly loves, / [...] had scratched her slender hand with a golden brooch'). ${ }^{15}$ Clearly, in this passage of the Iliad Kypris is defined by the male gods who defend her and by the goddesses who dismiss her as a fighter, although weaker than a mortal man, as well as a seducer of mortal women to transgressive sexual behavior, in each case exposing herself to grievous experiences.

In Sappho, by contrast, Aphrodite is never dismissed nor does she need to be defended. Through the title 'Kypris', in particular, she is presented, in the three fragments besides the new poem in which this title appears, as a strong ally and close partner of the poetic persona. Remarkably, in none of these does the goddess seem to be directly concerned with the erotic sufferings of the poetic persona herself, as is the case in the new Kypris poem.

In all three of the hitherto known Kypris poems (fragments 2, 5, and 15), as in the new one, the goddess is addressed; however, the invocation is not to be found at the beginning of the poem in any of these fragments. It seems to be a common feature of these poems, unlike the new Kypris song, that the invocation only appears near the end, functioning as a triumphant culmination that stresses the intimate connection between the poetic persona and the goddess. Thus in the last stanza of fragment 2, after evoking the enchanted landscape of an aphrodisiac sanctuary, Kypris is invoked (v. 13) to appear there

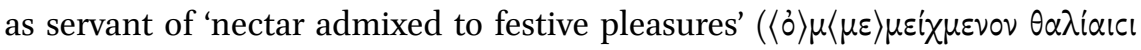

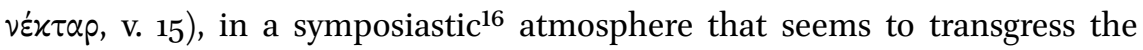

15 Il. 5.422-423 and 425. Athena's formulation in v. 423 partly repeats the one of Aphrodite in Il. 3.415 telling Helen that she still 'now exceedingly loves' her ( $\nu$ $v$ है $\chi \pi \alpha \gamma \lambda \alpha \varphi$ 'i $\lambda \eta \sigma \alpha)$.

16 The symposiastic character of the last stanza of fr. 2 is clearly emphasized by the role of Kypris as cupbearer who is summoned to pour nectar into golden cups. The song does not specify, however, that persons other than the poetic persona are to be served the drink of the immortals by the goddess. Neither an audience nor human companions are addressed or even mentioned. On the connection of Sappho's poetry with the symposium and especially with the world of hetairai associated with it: see Schlesier (2013) and (2014a) 191-202. Cf. Yatromanolakis (2004) 69, according to whom in Sappho's fr. 2 and fr. 94 a 're-enactment of symposiastic snapshots draws on cultural discourses and imagery relating to banqueting rituals'. See also Bierl (2011b) 139. Sappho's poetry was undoubtedly performed at symposia of later periods. However, several contributors to this volume, with the exception of Bowie, deny this for Sappho's lifetime. 
boundaries between mortals and immortals, although exclusively with regard to the poetic persona.

In fragment 5 (now augmented thanks to one of the new papyri) ${ }^{17}$ Kypris, while not addressed in the beginning (as had often been assumed after its first discovery on a papyrus) is finally addressed in the last stanza (second half of v. 18): c ¿ $[\delta] \grave{c}$ Kú $\pi[p] !$ apparently points to the safe return of a brother and to his former mistakes, it seems probable that Kypris is invoked here in order to close the poem with a positive perspective. What remains unclear, however, is the reading of the next

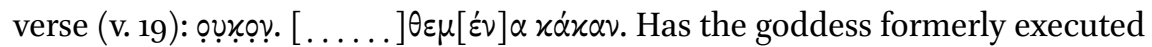
something 'bad' ( $x \alpha \dot{x} x \alpha$, as adj. acc. fem., associated to a lost noun, or as noun acc. fem. or else gen. plur.) that is oủx övexนov (West: 'insupportable'), and should she now be ready to offer a reversal, granting the wish of the poetic persona (so the prevailing hypothesis about the content of v. 20, the last of the poem)? Or should the goddess 'lay off' something unpleasant (in a gesture comparable to her 'laying down the anger', while being called 'violet-breasted', in another poem)? ${ }^{19}$

In fragment 15, Kypris is also addressed, and likewise in the last stanza, but this time she is invoked as an ally not in support of another person, but against a woman, ${ }^{20}$ who, according to the poetic persona, should not be allowed by the goddess to boast of being granted a further success in love.

As for the title 'Kyprogenea' in Sappho, the picture which emerges is even more elusive. Although it is possible that in fragment 22.16 the goddess is invoked rather near the end of the poem, before a stanza in which the poetic persona expresses her wishes - which ones, though, is not clear-, one cannot be sure that this stanza closes the poem. The one-verse fragment 134 possibly

17 See Burris, Fish, and Obbink (2014) 11 and 23-27, West (2014) 5-7, Ferrari (2014) 4-9, Obbink (ch. 1, this volume). Cf. the translation in Rayor and Lardinois (2014). On the first attestation of fr. 5 and its diverse restorations see Voigt ad loc.

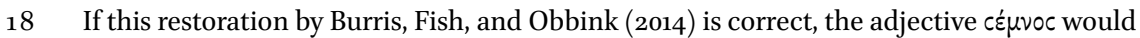
by now be a hapax in the extant poetry of Sappho and Alcaeus. See, however, Snell's restoration (with the epithet following the title) $\beta[\alpha] c i \lambda[\eta \alpha$ cह́ $\mu] \nu \alpha$ in Sappho fr. 65.6, compared to fr. 66c.1 $\mu \nu \alpha$ (Voigt ad loc.).

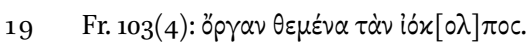

20 The reading of the name Doricha, in fr. 15.11, seems sound, pace Lidov (2002). On this name and the identification of Doricha as a hetaira, lover of Sappho's brother Charaxos in ancient tradition, see Schlesier (2013) passim. Kypris is addressed in fr. 15.9, but since the beginning of the poem is missing, it cannot be excluded that she was already mentioned before. 
consists of an address to the goddess, 'I talked with myself through a dream,

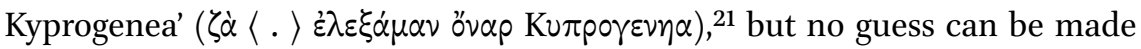
about the position of this single verse in a particular poem. The incomplete word Ku$\pi \rho \circ$ at the beginning of the first verse of fragment 44 (of which at the end, only two other letters, $\alpha c$, are preserved) does not allow to decide if this line included the title 'Kyprogenea', or if a paraphrase, like 'queen on Cyprus' (as in fragment 65.6), would be a more plausible supplement. ${ }^{22}$

Before considering the new Kypris poem in detail, it remains to turn to the instances where the name of Aphrodite is explicitly mentioned. ${ }^{23}$ In contrast to the consistent use of 'Kypris' and 'Kyprogenea' in Sappho's poetry, some of the seven fragments in which the name 'Aphrodite' appears employ it in contexts that are not directly associated with the close relationship between the poetic persona and the goddess (fragments $96,102,112$ ). These fragments seem rather to mention the name of the goddess in a descriptive, almost objective manner: in fragment 96.26 the very mutilated context could suggest that here Aphrodite is pouring nectar, ${ }^{24}$ as in fragment 2. The two-verse fragment 102 consists of an address to a 'sweet mother' and explains the erotic longing (pothos) of a girl as provoked by Aphrodite. ${ }^{25}$ In fragment 112, a bride (or a groom?) is addressed as particularly favored by Aphrodite. ${ }^{26} \mathrm{~A}$ further fragment, again poorly preserved, in which the name of the goddess appears (fragment 73a.3), does not allow to decide if she is presented here as involved with the poetic persona ${ }^{27}$ or not.

The remaining three fragments with the name 'Aphrodite' (fragments 1, 33 , 133b), however, unmistakably emphasize a privileged connection with the goddess. Two of them are addresses to her, and in the third (fragment 133b) the poetic persona is addressed by name (the speaker is presumably the goddess

21 On the term $\delta 1 \alpha \lambda \varepsilon$ $\gamma \circ \mu \alpha \mathrm{l}$ (here used in tmesis), later prominent in philosophy and rhetoric, cf. Tzamali (1996) 465-466. See also ibid. in defense of the vocative Kyprogenea.

22 For metrical reasons, Kyprogenea seems less probable. A bare mention of the island of Cyprus, however, should certainly be discarded, since there would be no plausible relation to the wedding of Hector and Andromache, the topic of this fragment.

23 On the only other title of Aphrodite in Sappho, 'Kytherea', see above, n. 9.

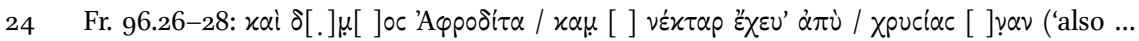
Aphrodite / ... poured nectar from / a golden ...').

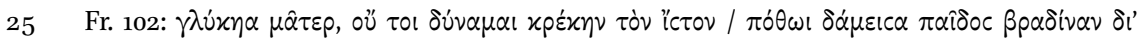

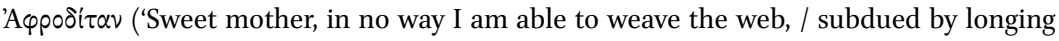
after a youth because of supple Aphrodite').

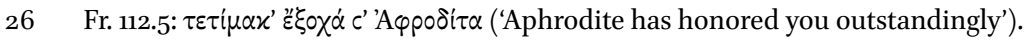

27 I would assume, however, that this could actually be the case. 


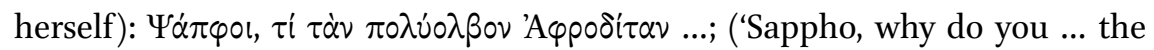
much-blissful Aphrodite?'). ${ }^{28}$ The address to Aphrodite in fragment 33 sounds

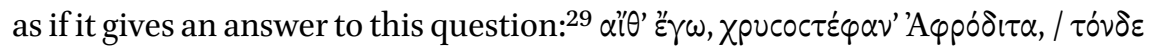
$\tau \dot{v} \nu \pi \dot{\lambda} \lambda \circ \nu\langle\ldots . . .\rangle.\left\langle\alpha \chi \alpha^{\prime} \eta \nu\right.$ ('If only, golden-garlanded Aphrodite, I could obtain ... this lot'). In my view, both these fragments create the impression that here the invoked or invoking Aphrodite is not so much concerned with a love affair, but rather with a particularly ambitious, self-reflective and religious interest on the part of the poetic persona, pointing rather to the latter's own claim to immortality and focussing above all on the goddess's belonging to the powerful Olympian gods, providing her with an eminent status as daughter of Zeus. Yet this could also be true of fragment $1,{ }^{30}$ in which Aphrodite is already addressed in v. 1 and in v. 20 addresses 'Sappho' in turn.

But what about lovesickness and the topic of recurrently unrequited and lost love or else of an absent beloved, themes so prominent in Sappho as also in the male lyric poets of the archaic period? ${ }^{31}$ It is striking that such themes are not associated with Aphrodite by her male colleagues and that in her own extant work, they are less often related to the goddess than one

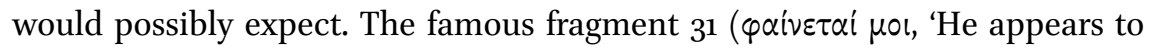
me $[\ldots]$ '), where the female 'I' is presented as a disregarded, terribly suffering lover confronted by a man and a woman erotically involved with each other, does not seem to have mentioned Aphrodite (or else Eros) whatsoever. ${ }^{32}$ Nor

28 This line is counted as second and last verse of fr. 133 in current editions, but it probably belongs to a different poem than fr. 133a. Note that Aphrodite receives here the epithet used in the 'Brothers poem', v. 20[16], for those humans who could hope to be turned

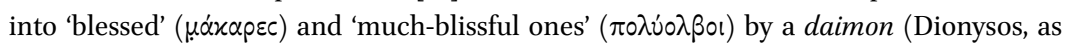
suggested by Obbink?) sent by Zeus. I am not convinced by the biographical interpretation of West (2014) 9, that mere material interest in 'the family's fortunes' is at stake here. In fr. 133b, at any rate, the adjective does not have to do with wealth, but rather with religious bliss, and likewise, I would contend, in the 'Brothers poem'.

29 Though the two fragments cannot belong to the same poem, since their meters do not match.

30 As I argued, in more detail, in Schlesier (2011a) and (2011b), also with regard to the new poem on the Cologne papyrus and its scholarly discussion. See further Schlesier (2014b) 293-295.

31 See Cyrino (1995). Note that the common scholarly opinion that Sappho's poetry is to be characterized by unrequited passion for female adolescents cannot be substantiated by the extant evidence-now including the Kypris poem-, as has been argued by Parker (1993). For a criticism of Parker's arguments see Lardinois (1994).

32 I am not convinced by the speculative assumption of D'Angour (2006) 300 and (2013) 64, $7^{0-71}$, that Aphrodite might have been addressed in the lost stanza(s) at the end of fr. 31 . 
is the goddess explicitly included when the poetic persona complains about the rejection of her love by a particular human. ${ }^{33}$ The experience of longing for an absent beloved expressed by the term pothos is almost never, in Sappho's hitherto extant work, explicitly connected with the goddess (or with Eros), ${ }^{34}$ although the fragments containing this terminology are mostly too short or too mutilated to exclude this in principle. Conversely, as in the male archaic poets, in Sappho as well it is rather Eros, not Aphrodite herself, who is declared responsible for the erotically excited physical and psychic state of the loving poetic persona. ${ }^{35}$

On the other hand, before the discovery of the new Kypris song a complete poem in seven Sapphic stanzas - the so-called fragment 1-was long known, having been transmitted continuously from antiquity thanks to its quotation by the rhetorician Dionysius of Halicarnassus. ${ }^{36}$ In this poem, as in the new one, lovesickness and the invocation of Aphrodite by her name as helper of the poetic persona is the central topic. However, the relationship of past and present in this song which takes the form of a prayer is a matter of debate. For sure, five stanzas of this poem, all but the first and the last, display recurrent situations in which the goddess payed attention to 'Sappho's' call, again and again coming to her aid in the state of unrequited or lost love. But these former epiphanic situations are clearly located in the past, and it does not necessarily follow that the present request of epiphany is occasioned by the same cause. ${ }^{37}$ It seems at least possible that something much more ambitious, immortality, is at stake here, and if this is the case, it would distinguish this poem from the new Kypris song, in which the present invocation of the goddess could actually be connected with unrequited love.

In addresses: fr. 71.1 (Mika), fr. 131.1 Lobel and Page (Atthis). Cf. fr. 88, fr. 129a, and fr. 129b, where the gender of the (anonymous) addressees is however not clear. See also fr. $168 \mathrm{~b}$.

34 Pothos: fr. 22.11, fr. 36, fr. 48, fr. 94.23. For an exception see however fr. 102; cf. also fr. 15.11.

35 Fr. 47 , fr. 130 (and possibly fr. 21.8). Cf. fr. 172 (Eros $\alpha \lambda \gamma \varepsilon \sigma i \delta \omega \rho o c$, 'giver of pains'). See, however, the glorious view of Eros (or eros?) in fr. 58.26 as well as the presentation of Eros

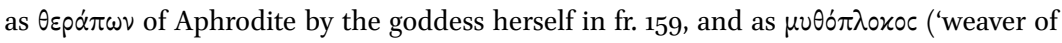
tales') in fr. 188. Cf. Eros as 'coming' ('ُ $\lambda \theta 0 \nu \tau \alpha)$ god in fr. 54. On eros (or Eros?) see also fr. 15.12 , fr. 23.1 , fr. 112.4.

36 A fragmentary Oxyrhynchus papyrus (P. Oxy. 2288) corresponds to vv. 1-21 of fr. 1. 


\section{On the Text of the New Kypris Song}

In light of the hitherto existing ample evidence for Aphrodite and her titles in Sappho's poetry summarized above, the new Kypris song is of course a most welcome supplement that deserves to be thoroughly examined, as will be attempted now. Because this poem on P. Sapph. Obbink is directly contiguous to the 'Brothers Poem' and separated from it by a mark functioning as a coronis, there is no doubt that the papyrus reproduces the first two stanzas of the 'Kypris Poem'. The text has been read and reconstructed by Obbink as follows: ${ }^{38}$

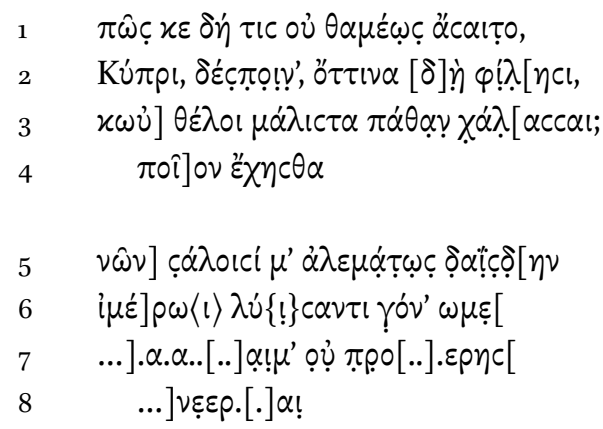

Since it overlaps in part with another papyrus (P. Oxy. 1231, fr. 16), ${ }^{39}$ two further fragmentary stanzas are to be taken as addition of the new text:

38 The text of v. 3 differs from his editio princeps in Obbink (2014b), where he had printed

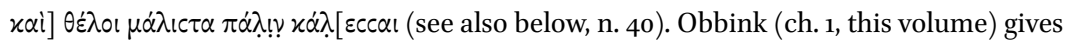
the decisive formal reasons for the new reading: $x \alpha i$ is 'too short for the space' (as is $\dot{\omega} c$, suggested by Ferrari), $\pi \dot{\alpha} \lambda \underline{\imath} v$ cannot be right, since $\theta$ is 'confirmed by multi-spectral imaging', and at the beginning of the last word, $\chi$ as well as $\chi$ can be read. He justifies the restorations (suggested by Lidov) of $\pi \dot{\alpha} \theta$ - as $\pi \dot{\alpha} \theta \alpha \nu$ with recourse to Pindar ('gen. pl. of Pindaric $\left.\pi \dot{\alpha} \theta \eta^{\prime}\right)$, and of $(\chi) \alpha^{\prime} \lambda$ - as $\chi \chi^{\prime} \lambda .\left[\alpha c c \alpha\right.$ l with recourse to the use of $\chi \alpha \lambda \alpha^{\alpha} c c o \mu \varepsilon v$ in Alcaeus, fr. 70.10. See below for my arguments in favor of another restoration of this verse.

39 This had previously been edited as a fragment of fifteen verses (= fr. 26) by Lobel and Page (1955) and Voigt (1971), vv. 11-12 being supplemented from Apollonius Dyscolus (Pron. 64b) and Herodian (On anomalous words $\alpha$ 24.6). These editors had also included as vv. 2-4 a quotation from Et. Gen., a choice which turned out to be erroneous in light of P. Sapph. Obbink. Thanks to another new papyrus, it is now obvious that the Et. Gen. quotation belongs to another fragmentary poem, counted as fr. 16a (formerly fr. 16.21-22 and 2832 ) by Burris, Fish, and Obbink (2014) 5 and 9. See also Obbink (2014b) 49, West (2014) 3 , and Obbink (ch. 1, this volume). The new Kypris poem overlaps with several letters and syllables of all first eight verses of P. Oxy. 1231 F16, which in turn provides parts of six more verses. Some missing letters of the Kypris poem were supplemented thanks to 


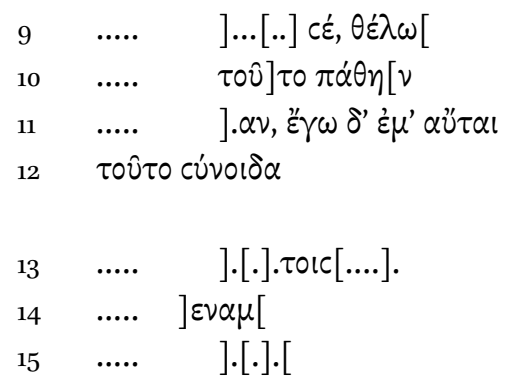

Obbink translates the three partially readable stanzas as follows: ${ }^{40}$

How can someone not be hurt and hurt again, Kypris, Queen, whomsoever one really loves, and not especially want respite from suffering?

What sort of thoughts do you have

to pierce me idly with shiverings out of desire that loosens the knees ... ... not ...

$$
\begin{aligned}
& \text {...] you, I wish [ ... } \\
& \text {...] to suffer this [ ... } \\
& \text {...]. This } \\
& \text { I know for myself. }
\end{aligned}
$$

Clearly, the poem is incomplete. The first two verses of the fourth stanza are extremely mutilated, the last two missing-hence this stanza is not recoverable at all-, and the poem could have continued with one or more (up to three) stanzas. ${ }^{41}$

this previous evidence. Therefore, the following readings are secured: v. $1 \omega$, v. 2 ő $\tau \tau \imath \alpha$, v. 3

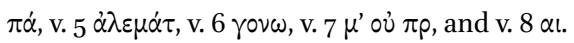

40 Obbink (ch. 1, this volume). Cf. the text and translation of the editio princeps: Obbink (2014b) 49 (cf. 37-39), with his comments 45-49; there he gave the following translation of vv. 1-3: 'How wouldn't anyone feel anguish repeatedly, / Kypris, Queen, and especially wish to call / back, whomever one really loves?'

41 A length of seven stanzas is attested for fr. 1, the opening poem of Book 1 of the Alexandrian edition of Sappho. However, this is not to be considered as the standard length of songs in this book. Fr. 5 , fr. 17, and possibly also fr. 16, only contain five stanzas. Six or seven stanzas 
As alternatives to Obbink's reading in his editio princeps ${ }^{42}$ of some parts of the new papyrus text, other suggestions have been made, especially by West and Ferrari. They offer the following conjectural versions of the first two stanzas:

The version of West: ${ }^{43}$

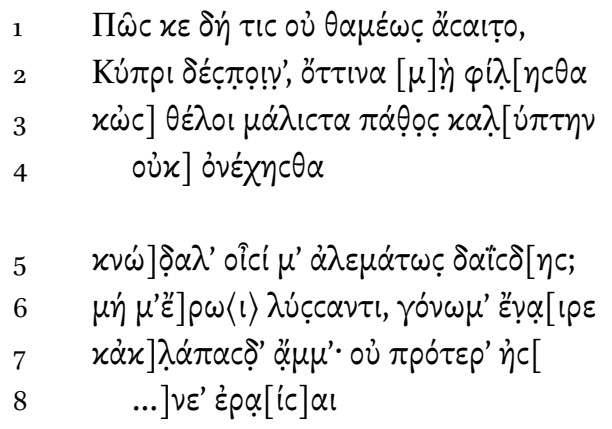

West's translation:

How can a woman help being regularly heartsick, my Lady, if you do not love her, and when she would most wish to conceal her passion, you do not hold back the mordacious pests with which you ravage me to no purpose? Do not, I beseech you, despoil me with raging love and devastate us. You were not previously ... to me when I was in love.

\section{The version of Ferrari: ${ }^{44}$}

$1 \pi \hat{\omega} c \varkappa \varepsilon \delta \dot{\eta} \tau \ll \subset$ ○ं $\theta \alpha \mu \varepsilon \dot{\varepsilon} \omega c \ddot{c} c \alpha i \tau 0$,

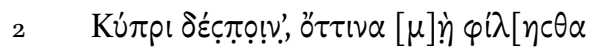

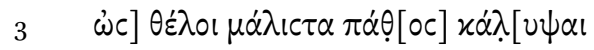

$\left.4 \quad \mu \eta \delta^{\prime}\right]$ o $\left.v^{2} \chi \eta\right\rangle \subset \theta \alpha$

could be assumed for the 'Brothers poem' of which the last five stanzas are preserved. Therefore, the new Kypris song may have had five, six, or seven stanzas.

42 The translation in Rayor and Lardinois (2014) was based on this reading. Cf. now Rayor's new translation (in this volume) based on Obbink's new text in v. 3.

43 West (2014) 12; see also 9-12 with his textual arguments and interpretative suggestions.

44 Ferrari (2014) 13, including suggestions and translations for the third and fourth stanzas as well as an apparatus. Unlike Obbink and West, though, he does not accept an enjambement of the first stanza with the second; see furthermore 13-15 with his comments. 


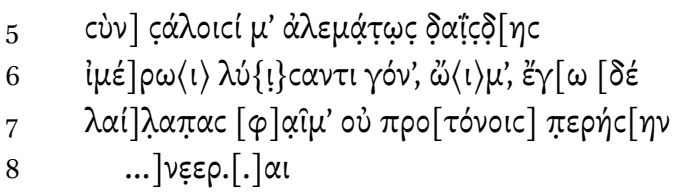

Ferrari's translation:

Come non si cruccerebbe più volte, Kypris padrona, chiunque tu non favorisci quando in sommo grado vuol celare la sua passione né lo trattieni?

Fra sussulti ondosi tu vai straziandomi con il desiderio che, ohimé, già mi piegò le ginocchia, ma io credo che le raffiche non sopravanzeranno gli stralli se ......

Obviously, there are important divergences between these three scholars. Even when they agree on the text, the translations sometimes turn out to be quite different.

Textually speaking, West and Ferrari agree with Obbink's editio princeps especially on the reading of v. 1. Concerning the rest, the disagreements affect above all the proposed supplements of letters at the end and the beginning of incomplete verses, but in some cases also the insecure reading of letters and the construction of words in the middle of verses. On the whole, there is more agreement between West and Ferrari than between the two of them and Obbink, especially concerning verses $2-4$.

The textual suggestions are not least shaped by the interpretative conception of the poem, in other words, by the idea each individual scholar advocates concerning what Sappho presumably wanted to express. Yet the poem, especially the first stanza and its possible enjambement with the second stanza, conveys syntactical problems too. Remarkably, this is also the case for the preceding poem on this papyrus, the 'Brothers Poem', that displays instances of idiosyncratic syntactic constructions that cannot easily called into question, since the transmitted text contains almost no lacuna. While Ferrari reads vv. 14 of the Kypris Poem as one single interrogative sentence, West includes in it also v. 5 and, finding this long sentence-especially the intervening clause in vv. 2-3- too complicated, suggests another quite odd complication: a change of verb from third person in v. 1 to second person in v. 2 and then back to third person in v. 3 and once more back to second person in vv. 4-5 (all those changes 
being also adopted by Ferrari). None of this is self-evident. In my view, the option of dividing the first six verses into two sentences (actually two questions, each with a grammatically different subject) of three verses each, the first with three third-person verbs, the second with one single second-person verb, as proposed by Obbink, is defendable for reasons I am going to develop presently.

West's and Ferrari's assumption that the first sentence consists of four or even five verses compelled them to restore the last word of v. 2 as a secondperson verb ( $\varphi$ i $\lambda \eta{ }_{i} \theta \alpha$, 'you love', 'tu favorisci'), assuming that it addresses Kypris who is actually invoked in the beginning of this verse. From that it ensues that West and Ferrari need to introduce a negative particle, because, as they want to believe, the situation described in v. 1 is incompatible with the goddess' love for a person and rather points to the contrary. There are at least two objections to this interpretation: first, a statement saying that a loving person is N от loved by Aphrodite would be in harsh contrast to all what we know from Sappho's poetry about her idea of love and particularly her own relationship to the goddess, ${ }^{45}$ and is therefore highly unlikely. Even in descriptions of suffering from the most painful lovesickness, the poetic persona never criticizes Aphrodite nor concludes that she is not loved by her. All the more so since love, in Sappho as in other archaic poets, is not considered as something that excludes pain by definition, but quite the opposite. Second, the negation supplemented by West and Ferrari in v. $2([\mu] \dot{\eta}$, 'not', instead of $[\delta] \eta \dot{\eta}$, 'indeed'), cannot convincingly be justified as avoidance of a repetition, devaluated by West as 'inelegant' after a first $\delta \dot{\eta}$ in v. $1 .{ }^{46}$ Much of Sappho's extant poetry indicates that, quite to the contrary, one of its significant stylistic traits is actually emphatic repetition (of particles, pronouns, adverbs, and other linguistic features), and that Sappho uses this formal device even poetologically. This is frequently connected with one of the topics she shares with her male poetic colleagues, i.e. iterative and promiscuous love, for which the emphatic term $\delta \eta \hat{\tau} \tau$ ('indeed again') is emblematic. ${ }^{47}$ In fragment 1 , Sappho even repeats this term thrice in close

45 See above, the first section of my paper.

46 West (2014) 10. On correlations of the emphatic particle $\delta$ ' ('indeed') in archaic poetry see Obbink (2014) 47. See also, as possible intertext here referred to by Sappho: Hom. Il. 5.422 (with a single $\delta \dot{\eta}$ ), quoted above. The repetition of $\delta \dot{\eta}$ will later be inflationarily used by Plato in the Phaedrus (273c), when he mockingly reproduces the rhetorics of a lawcourt dialogue. Cf. Benelli (2015) agreeing with Obbink in keeping the second $\delta \dot{\eta}$ (to be followed, however, by West's and Ferrari's $\varphi(\lambda)=\theta \alpha)$.

47 See the illuminating study by Mace (1993). 
proximity. ${ }^{48}$ If a comparable repetition by means of the doubling of $\delta \eta$ in vv. 1 and 2 is to be found in the new Kypris poem, this would further emphasize, even on a formal level, the lasting semantic impact ${ }^{49}$ of the adverb $\theta \alpha \mu \varepsilon$ ' $\omega c$ ('repeatedly') used in v. 1 close to the first $\delta \dot{\eta}$.

The conviction that in accordance with conventional syntactical and rhetorical rules the subject of the first sentence changed in v. 2 constrains West and Ferrari to a further odd interpretation: they claim that Sappho must have expressed here the wish 'to hide her passion'. I think that, like myself, many other readers of Sappho will be baffled by this supposition. West writes that 'it is a commonplace of ancient literature that the lovestruck try initially to conceal their condition' and adduces as confirmation a series of quotations, starting with the Theognidea and Euripides' Hippolytos and continuing with examples from the Roman empire to the Byzantine period..$^{50}$ The trouble is that this 'commonplace' is never found in Sappho. From her poetry it is obvious that concealment of erotic passion is by no means her concern. On the contrary, she exposes it overwhelmingly and even exhibits her name 'Psappho' proudly and sarcastically as eventually defined by an erotically raving state of mind, $\mu$ alvó-

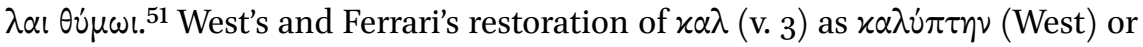
$\chi \alpha \dot{\lambda} \nu \psi \alpha_{l}$ (Ferrari), i.e. 'to hide', should therefore be discarded. Furthermore, this makes their supplement to the preceding letters, $\pi \alpha \theta$ (v. 3), read as $\pi \dot{\alpha} \theta$ ọc ('passion'), equally unconvincing. There is really not much in favor of this guess. West himself admits that this would be the first instance of the noun (which in fact is not attested before Aeschylus). ${ }^{52}$ Obbink now suggests the restoration $\pi \dot{\alpha} \theta \alpha \nu$ ('sufferings', gen. plur. of $\pi \dot{\alpha} \theta \alpha$ ), associated with $\chi \dot{\alpha} \lambda$ [ [ $\alpha c c \alpha$ ( ('to relax'), although he acknowledges that $x$ - and $\chi$ - are both paleographically possible. ${ }^{53}$

48 Fr. 1.15, 16, 18: this is part of questions in indirect discourse by which the 'Sappho' of this poem renders the enquiries Aphrodite used to address to her.

49 This impact of $\theta \alpha \mu \varepsilon^{\prime} \omega c$, as expressed in the repetition of $\delta \dot{\eta}$, would receive even greater emphasis by the repetition of $\pi \dot{\alpha} \theta \eta \nu$ (v. 3 and v. 10), and by $x \dot{\omega} c$ (v. 3) echoing $\pi \hat{\omega} c$ (v. 1). See below, nn. 61 and 78 .

50 West (2014) 10. Cf. Ferrari (2014) 14.

$5^{1} \quad$ Fr. 1.18 - in response to Archilochus' disparaging presentation of a (heterosexually) sex-

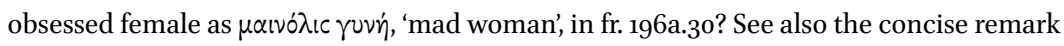
on Sappho by O'Higgins (2003) 87, in her pertinent chapter about 'Women's iambic voices': 'There was something in her style and subject matter that drew her into the orbit of Archilochus and the others.'

52 Cf. Benelli (2015) who accepts West's $\pi \dot{\theta} \theta 0 c \kappa \alpha \lambda \nu \dot{\tau} \pi \eta \nu$. On $\pi \dot{\alpha} \theta 0 c$ in Aeschylus see Schlesier (2009) 86-90. Cf. also the fem. noun $\pi \dot{\alpha} \theta \alpha$ first attested in Pindar, e.g. Ol. 6.38.

53 For Obbink's arguments justifying his new restoration see $n .38$ above. However, another

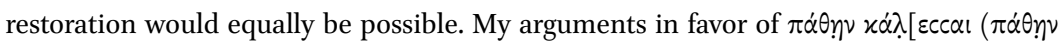


As a result, there would be no compelling reason to deny the possibility that the first sentence ends with v. 3 and is governed only by third-person verb forms. It comes as a surprise that this sentence is interrupted in $\mathrm{v} .2$ by the invocation of Kypris as 'mistress' ( $\delta \varepsilon \dot{c} \pi \circ v \alpha)$. As a matter of fact, such a combination of an aphoristic utterance with an address is a typical feature in iambic and elegiac poetry (as attested in Archilochus and the Theognidea), but is never combined with an address to a deity. ${ }^{54}$ Against this background, it is striking that in Sappho's new Kypris poem, an authoritative statement is conveyed to the goddess in the same way as male archaic poets convey such statements to their human companions. Moreover, if Obbink's restoration is correct, the vocative Kú $\pi \rho t$ is followed by $\delta \varepsilon \varepsilon c \pi o v v \alpha$, unheard-of before in ancient tradition as a divine epithet. ${ }^{55}$ According to Obbink's reading, the goddess is then addressed by a second-person verb only in v. 4 (' $\varepsilon^{\prime} \chi \eta c \theta \alpha$, 'you have'), the beginning of a second sentence, continuing until v. 6. If this corresponds to what Sappho has composed, it really is a bold poetic maneuver of cross-over, formally linked

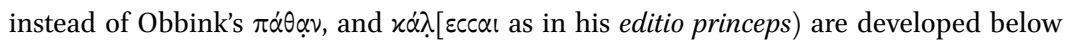
(with nn. 6o-61). I do not see why West (2014) 10 considered $\pi \dot{\alpha} \theta \eta \eta v$ as too long for the space on the papyrus.

54 Gnomic statement plus vocative: in Archilochus, fr. 13, fr. 14, and fr. 15 (the addressees are presented as male companions of the poetic persona, Pericles, Aesimides, and Glaucus). See also often in the Theognidea, e.g. $77^{-7} 8$ and $1353^{-1356}$, and with vocative at the beginning of the second line of the statement, as in Sappho's new Kypris song, and no second person singular in the sentence: 117-118, 119-120, 329-330, 1219-1220 (the addressee is Cyrnus). To my knowledge, before Sappho the only instance of an apostrophe of a deity combined with an aphoristic statement is to be found in Hom. Il. 17.19-21, although the direct addressee of the speaker Menelaus is not Zeus, here invoked by a vocative, but the Trojan warrior Euphorbus.

55 Never before Sappho is despoina attested as an epithet for Aphrodite or for that matter for any goddess (Obbink [2014b] 47, West [2014] 10). See also the address to Hermes in Sappho, fr. 95.8: $\hat{\omega} \delta$ $\delta \dot{c} \pi 0 \tau^{\prime}$ (first attestation as title of a male deity). In Homer, despoina typically specifies powerful queens. On the hitherto existing evidence for this epithet, also used as name, see Henrichs (1976) adducing on p. 263 Anacreon fr. $348.2-3$ as first evidence of the term for a goddess so far (here applied to Artemis as 'mistress of wild

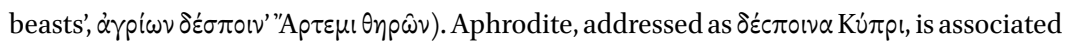
with illicit erotic practices in Eur. Hipp. 415 and with the promiscuous sex of prostitutes (who designate young men e.g. as $\dot{\alpha} \pi \varphi \dot{\alpha}$ pı $\alpha$, 'little brothers') in middle comedy (Xenarchus, fr. 4.21, with v. 15). In epic, Kypris never occurs with an epithet, and the epic epithets used for Aphrodite regularly precede the name of the goddess (see Boedeker [1973] 20 and 2225) and do not follow it. For an exception see Hymn. Hom. Ven. 1-2 (above, n. 12): Kypris following the name Aphrodite. Cf. also above, n. 18, and Sappho's fr. 1.1-2 where Aphrodite is not only preceded by two epithets, but also followed by two others. 
up with an enjambement between the first and the second stanza (vv. 45): in a sophisticated manner, an emphatic postponement of the goddess' decisive reasoning and behavior takes place that creates a brief suspense while Kypris, the divine subject of the second-person verb, has been anticipated and nominally revealed already two verses before, by a vocative intervening in v. 2 , in the form of the most ancient title of the goddess connected with an epithet that would stress her human-like and human-related rulership.

Thus the first sentence turns out to function as a general gnomic utterance that is imparted to the goddess as being true for every human in corresponding situations and therefore skillfully cast as a "rhetorical" question, ${ }^{56}$ but not a 'cri $d u$ coeur, ${ }^{\prime 57}$ as Ferrari assumes. Moreover, this analytical statement is far from being restricted to 'a woman', as West presupposes in his translation. Sappho, at least, had felt no need to gender the indefinite personal pronoun $\tau \iota^{58}$ ('someone') in v. 1 (the unchanged subject, in Obbink's reading, of the sentence until its end in v. 3). But the acceptance of the gnomic value of this sentence, for human females and males alike, is perhaps mainly impeded by a refusal to take

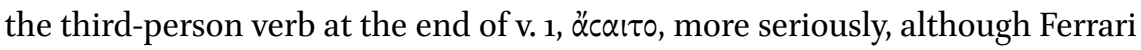
has rightly stressed the consistent connection of such a term with nausea in Sappho. ${ }^{59}$ Accordingly, Sappho is not talking of a person who is 'regularly heartsick', as West has it, or 'hurt and hurt again', as Obbink suggests, but 'frequently disgusted' - and against this background, the question "by what?" cannot be avoided. The reason cannot be just love or else being heartsick.

$5^{6}$ Such a question in which, as happens here with the $0 v$ in v. 1 , the negation is abolished by the implied affirmative answer, became, in the wake of ancient Greek tradition, one of the major persuasive and ironical devices of rhetoric and philosophy.

$57 \quad$ Ferrari (2014) 13.

$5^{8}$ In a comparable way, Sappho does not gender the same indefinite personal pronoun in fr. 1.18 and 19 either. For the impact of this deliberate practice on the message of this poem, therefore not pointing to exclusively female lovers of the poetic persona in the past, see Schlesier (2011a) 421-423.

59 Ferrari (2014) 13 also refers to other instances in Sappho's poetry of the asa-terminology (fr. 1.3, fr. 3.7), to which fr. 91 and fr. 103(8), and possibly fr. 68a.4, should be added, as noted by Obbink (2014b) 46-47-although he interprets $\ddot{\alpha} c \alpha \iota \tau$ as a reference to 'heartache and anguish' (with Page on fr. 1). In my view, however, such a mostly psychic meaning is far from certain (as is 'vertigo', suggested by Boehringer and Calame, in this volume). For the heavy physical implication of this terminology (pointing to surfeit and oversaturation in every respect) in Sappho as in the medical writers, see with regard to fr. 1 Schlesier (2011a) 424. The caustic asa-terminology is repeatedly used by Alcaeus as well (perhaps also in Archilochus, fr. 127). 
My tentative answer would take into account that here, a physical nausea seems to be issued not from physical surfeit, like too much drinking, eating, or sex, but apparently from a psychic impulse, the will to $\pi \dot{\alpha} \theta \eta \underline{y}$ xá $\lambda \varepsilon \varepsilon c \alpha a$ (v. 3), that is to 'call' 60 to the 'experience' 61 (of love) the person who is loved. By this token, a retrospective explanation is given why the $\tau \iota c$, in v. 1 , is 'frequently disgusted'. The wish to receive a 'respite from suffering' ( $\pi \dot{\alpha} \theta \alpha v \chi \alpha \dot{\alpha} \lambda[\alpha c c \alpha l$, Obbink), however, would not explain why the $\tau i c$ is not just upset because of its unreciprocated love, but, more specifically, disgusted. The disgust, I am arguing, is issued from his own heavy urge ( $\theta \dot{\varepsilon} \lambda$ ol $\mu \dot{\alpha} \lambda ı \iota \tau \alpha)$ to 'call' ( $\kappa \dot{\alpha} \lambda \varepsilon c c \alpha l)$ the belovedor more precisely: 'whomsoever (o' $\tau \tau \imath \nu \alpha$, v. 2$)^{62}$ is loved'-to respond to the love, that is 'to experience' ( $\pi \dot{\alpha} \theta \eta v)$ the same as the lover, for good or bad. Thus the lover is not only exposed to unreciprocated love, but is also, or even especially, disgusted because of his own reaction to such a situation. In other words: the lover is not already disgusted by the beloved's rejection, but by his own (the lover's) overwhelming psychic drive to react to it (by calling the beloved). Clearly, the unspecified experience to which the beloved is to be called can only be love. On that reading, this is it what Sappho, in a rather objective, almost

6o As a matter of fact, $x \alpha \dot{\alpha} \lambda[\varepsilon c c \alpha l$ was Obbink's first reading, and he does not exclude this reading even now. The verb is often used with a dependent infinitive ('to call someone to do something') since Homer, e.g. Il. 10.197, Soph. El. 996, Phil. 466. Here in Sappho, it would be an infinitive from which another infinitive $(\pi \dot{\alpha} \theta \eta \nu)$ seems to depend. A comparable, even more complicated idiosyncratic feature is to be found in the 'Brothers poem', vv. 8-13 [4-9] (six interconnected infinitives on three syntactical levels).

61 The verb $\pi \dot{\alpha}<\chi \omega$ is used also in two further poems of Sappho, and the infinitive $\pi \dot{\alpha} \theta \eta \nu$ (re)appears later in the Kypris song (v. 10, cf. below, n. 83). In Sappho, the verb typically

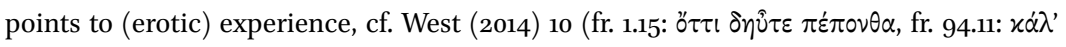
$\varepsilon \dot{\varepsilon} \alpha \chi \chi \circ \mu \varepsilon v)$. In fr. 94 the verb is used twice (already in fr. 94.4), as presumably in the Kypris song. It should be kept in mind that repetitions are one of Sappho's preferred stylistic devices. On repetitions (and other rhetorical features) in fr. 94 see Schlesier (2015). On the syntax of the Kypris poem's vv. 1-3 see below, n. 74 .

62 This relative, the object of the (implicit) subject $\tau ı$ in v. 2, is not gendered either. Sappho stresses here its generalizing value, as she does frequently elsewhere, especially in authoritative statements, for instance in fr. 16.3-4 (there as well, though in neuter form, depending on the non-gendered personal pronoun $\tau \mathrm{\imath c}$ ). See also fr. 31.2, where it is applied

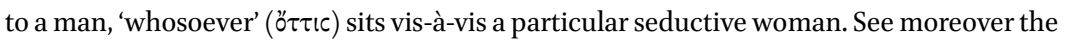

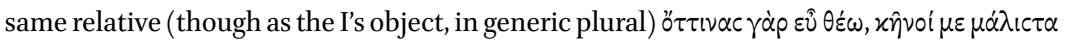

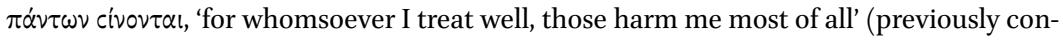
sidered as belonging to fr. 26, as its vv. 11-12, but now disclosed as part of fr. 16a, see above,

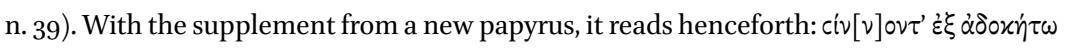
('harm unexpectedly'), cf. Burris, Fish, and Obbink (2014) 18. 
clinical report ${ }^{63}$ sketched in vv. $1-3$, is reminding her addressee Kypris, against the background of an appeal to the undeniable experimental evidence of an anthropologically informed diagnosis.

Yet this would not of course be the last word — at any rate, it stands right at the beginning of the poem. But is the poetic persona asking Kypris for a delivery from erotic assault, as West and Ferrari prefer to believe? Assuming this means being led by the imagination of a Sappho who emulates, avant la lettre, Euripides' Phaedra, a presumption that cannot be supported by anything in Sappho's extant work. And I doubt that the poet would have looked for a dissonant term designating beastly creatures $(\kappa v \omega \dot{\delta} \alpha \lambda \alpha)$, as West fancies, when she wanted to provide her raving love with an appropriate sound and shape. At any rate, one would not find in the rest of Sappho's transmitted corpus any evidence for the wish NOT to be exposed to such violent love or else to conceal it, nor for the idea that the goddess Aphrodite could be persuaded to hold it back from her, as if it were perpetrated by a bunch of ugly beasts. ${ }^{64}$

With the second question, when starting in v. $4,{ }^{65}$ the poetic persona rather breaks cover (which is not to be confused with a frustrated wish of concealment). Only now does she introduce herself explicitly, if only in the most minimalistic form of one single letter, with a generic first-person pronoun $(\mu \varepsilon$, acc. with elision, v. 5), and she describes graphically her own state as object of lovesickness: in v. 5 first in terms of a large-scale natural, almost cosmic, phenomenon, as if it were an earth-quake or a seaquake ${ }^{66}$ (editio princeps: cá $\lambda$ oıcl, 'shiverings', or 'tossings', accepted by Ferrari), and then, produced by it, as a

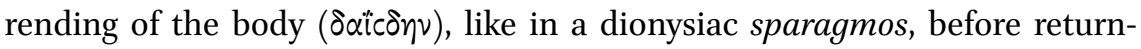
ing in v. 6 to the image of knees loosened by desire (editio princeps: i $\mu \dot{\varepsilon}] \rho \omega\langle\downarrow\rangle$ $\lambda u^{\prime}\{!\} c \alpha \nu \tau \iota$ yóv') or eros. This latter image displays an almost proverbial expression familiar from much archaic poetry, including Sappho's, that distinctively marks sexual arousal of males and females alike. Ferrari accepts this reading, but feels obliged in addition to impute to Sappho a tragedy- or opera-like regret

63 This report seems to be expressed in an ironical, if not an iambic manner. It could be compared with the one in fr. 31, in which O'Higgins (2003) 97 and 207, with reference to Aloni (2001) 31, aptly detected self-conscious irony.

64 In ancient tradition, however, not only Aphrodite herself, but likewise her servants and attendants are always beautiful.

65 In this case, it would be structured as anacoluthon that mimics natural speech.

66 For a similar conception of love, cf. Sappho's comparison of Eros with a tempest on the mountains in fr. 47. See also Ferrari (2014) 13-15 who thinks that v. 7 of the Kypris poem, as its v. 5 , may use seafaring metaphors for the raging love (which in any case is a central topic of the second stanza). 
that this is happening to her (his conjecture is $\ddot{\omega} \iota \mu$ ', 'ohimé, 'alas'), something that, I am afraid, cannot be conceived of on the basis of what we know of Sappho's poetry. The central importance of the adverb emphatically located in the middle of v. 5 , $\dot{\alpha} \varepsilon \mu \dot{\alpha} \tau \omega c$ ('in vain'), is then left unappreciated in Ferrari's translation, where it is simply omitted, while in West's translation it is associated with Kypris' putative sending of phantom-like monsters who ravage the speaking I 'to no purpose'.

However, with the supplements adopted by Obbink for the beginning of

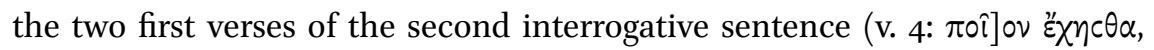
'what do you have', linking up with the next word, v. 5: $v \omega \mathrm{v}]$, 'thought'), ${ }^{67}$ the poetic persona is not begging of Kypris that she may nот be in love, as West and Ferrari presuppose, but rather is asking the goddess a serious question about the rationale behind her actions towards her. Here the meaning 'in vain' (rather than 'idly', as in Obbink's or Rayor/Lardinois's translation) ${ }^{68}$ is essential and even provides retrospectively the objective statement in the first sentence with an additional subjective clue. For when would the 'tearing apart' and the 'shakings' or 'wavy tossings' by means of erotic desire that Kypris dispenses be 'in vain' for the lovestruck I? Only if the beloved is not granted the same by the goddess, which explains why the lover would most of all want to call the beloved to the experience of love. By this token, a third question seems to be implied: "Why don't you, Kypris, transmit an erotic rage such as that targeted at me on the beloved, too?" Since in that case, the erotic rage of the 'I' would evidently not be 'in vain', but could eventually lead to gratification. In other words, what is at stake here is less an urge to relax from suffering, as Obbink argues (with the help of his restoration $\pi \dot{\alpha} \theta \alpha v \chi_{\alpha}^{\alpha} \lambda$ [accal), but rather the will of the lover that the beloved too turn into a lover rather than remain only a beloved. Hence, in that case, the reason for the lover to be disgusted would disappear.

If this reading is correct, the first six verses of this poem then display a sort of abbreviated love theory, a poetical analysis of the preconditions both for

67 Both supplements suggested by Bowie (apud Obbink [2014b] 48, cf. [v] $\omega_{0} v$ है $\chi \circ \mathrm{cc \alpha}$ : Sappho, fr. 96.2). Obbink ibid. also refers to another restoration proposed by L.A. Holford-Strevens: $\pi \hat{\omega} c]$ o $v^{\varepsilon} \chi \eta \subset \theta \alpha$ ('how do you keep on').

68 After rendering $\alpha \lambda \varepsilon \mu \alpha \dot{\alpha} \tau \omega \mathrm{c}$ by 'in vain', Obbink (2014b) 48 finally discards it, since he presupposes, erroneously in my view, that this would make the goddess 'not responsible'. I would argue, however, that the opposite is true (for Kypris' presentation in this poem, the notion of "irresponsibility" offers a better fit). By contrast, the speaking human is defined by responsibility of thoughts, formulated first as a rhetorical question, and second as a straightforward one, both communicated to the goddess. 
the unhappy, because not-reciprocated, love of a lover and for its opposite, shared enthusiastic satisfaction in love. ${ }^{69}$ Leaving aside the very mutilated verses $7-8$, which are only conjecturally recoverable, ${ }^{70}$ the words preserved in the third stanza (vv. 9-12) seem to confirm that, after the analytical miniature formulated in two three-verse questions, Sappho finally advances even more explicitly in the same direction: that is, an intellectual self-reflection ${ }^{71}$ about love-deliberately communicated to the goddess by the poetic persona as in an intimate conversation between almost equal partners, without any religious awe-, in accordance with a compositorial structure one finds in others of her songs as well, as has often been noted in scholarship.

As a result of this discussion, I would provisionally suggest the following translation, ${ }^{72}$ based mainly ${ }^{73}$ on the text of the editio princeps whose readings, I think, could be vindicated: ${ }^{74}$

69 If this is what is at stake here, it would invalidate psychological assumptions about Sappho as a person whose biography could be reconstructed with the help of her poems. Therefore I doubt that the Kypris poem may directly document 'the poet's own feelings', as Obbink (2014b) 34 asserts.

70 Just one remark on them: Tsantsanoglou (apud Obbink [2014b] 48) has suggested the reading $[\varphi] \alpha i \mu$ ', 'I would say', in v. 7 , adopted by Ferrari (2014) 13-14, who thinks that it was preceeded in v. 6 by an equally emphatic है $\gamma \omega$ (see however below, n. 102). This would certainly correspond to the feature of an authoritative speech gesture, something to be found repeatedly elsewhere in Sappho (cf. especially fr. 16.3-4, and the Cologne papyrus with the 'Tithonos poem' on old age), a gesture that at any rate dominates the following third stanza. For further suggestions on the second stanza see Obbink's apparatus (ch. 1, this volume).

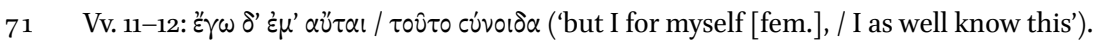

72 My translation aims to be no more than a line by line literal version, respecting, insofar as possible, the original word-order.

73 The most important divergence from Obbink's new text (see above, and Obbink, ch. 1, this volume) is my restoration in v. 3 of $\pi \dot{\alpha} \theta$ - as $\pi \dot{\alpha} \theta \eta \eta v$, not as $\pi \dot{\alpha} \theta \alpha \nu$. For the same verse, in

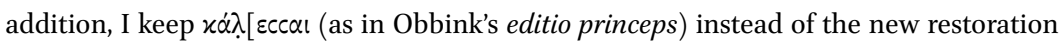
$\chi \dot{\alpha} \lambda[\alpha c c \alpha l$, and I adopt West's $\chi \dot{\omega} c$ instead of the new supplement $x \omega \nu$. See also nn. 38 and $60-61$ above, with $\mathrm{nn} .74$ and 78 below.

74 As for the first three verses, I take them (with Obbink) as a complete sentence (a question). The meaning of these verses, however, depends heavily on the restoration of the end of v. 2 and the beginning and end of v. 3. The reading of v. 1 and the beginning of

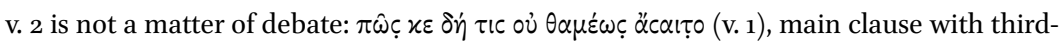

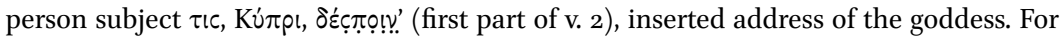
the rest of the sentence, the syntactical construction is complex and has been differently interpreted by scholars. A special crux is the relative clause following the address (second part of v. 2). Its relationship with the main clause in v. 1 and with the supplementary 


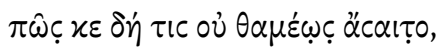

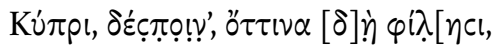

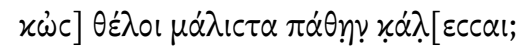
$\pi \circ \hat{]}]$ ov है $\chi \eta \subset \theta \alpha$

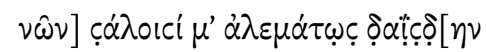

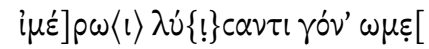

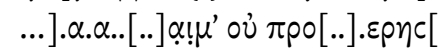

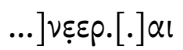
.... ]......] $\quad$ ć, $\theta \dot{\varepsilon} \lambda \omega[$
..... $\tau \circ \hat{v}] \tau \circ \pi \dot{\alpha} \theta \eta[\nu$
..... ]. ]. $\alpha \nu, \varepsilon^{\prime} \gamma \omega \delta^{\prime} \dot{\varepsilon} \mu^{\prime} \alpha \nu^{\prime} \tau \alpha l$

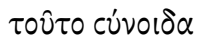

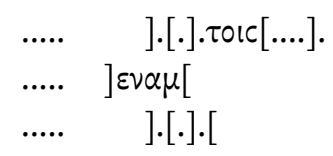

clause in v. 3 is problematic. West tries to remove the problem by means of a restoration

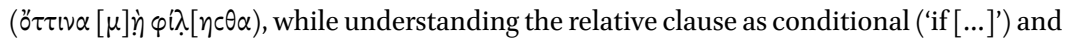
in continuation of the address. For semantical reasons, however, both the subject of the relative clause taken as second-person verb form and its negation are improbable, as are his and Ferrari's subsequent restorations of v. 3 (see my arguments developed above). In

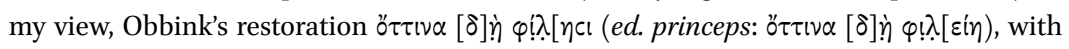

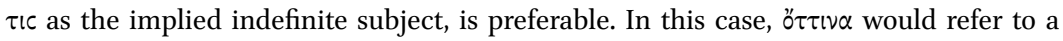
suppressed antecedent implied in the main clause. As for v. 3, Obbink's new restoration

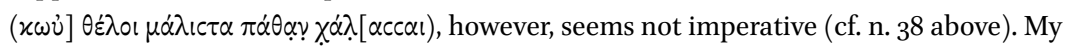

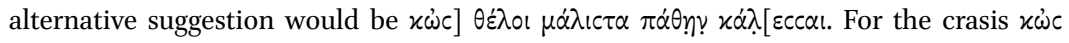
as alternative to Obbink's supplement $x \omega \nu$ see below, n. 78. For the restorations $\pi \dot{\alpha} \theta \eta \nu$ and $\chi \dot{\alpha} \lambda \varepsilon \varepsilon c \alpha \iota$ as alternatives to Obbink's $\pi \dot{\alpha} \theta \alpha \underline{\varphi}$ and $\chi \alpha \dot{\alpha} \lambda[\alpha c c \alpha l$ see nn. 6o-61 above. At any rate, $\tau \iota c$ functions here (again) as the implied indefinite subject. Moreover, ö $\tau \tau \imath \nu \alpha$, the object of $\varphi$ i $\lambda \eta$ cı in the relative clause, could maintain an impact on the following supplementary clause - as implied object of $\chi \alpha \dot{\lambda} \Omega \varepsilon c \alpha \iota$ and subject of $\pi \dot{\alpha} \theta \eta \nu$ - but a repetition of this indefinite (like the one of $\tau$ Ic) would be omitted (cf. Smyth [1984] §1980). For $\pi \dot{\alpha} \alpha \boldsymbol{\alpha}$ used absolutely cf. Hes. $O p$. 218. Note that in my reading of vv. 1-3, the effect$\alpha \ddot{c} \alpha \iota \tau$ - is expressed before the cause, whereas in Obbink's reading, the cause precedes the effect. On his questionable new identification of the verb in the main clause see below, n. 75 . 
1 How would one indeed not be frequently disgusted, ${ }^{75}$

2 Kypris, mistress, ${ }^{76}$ at whomsoever one loves indeed, ${ }^{77}$ even when ${ }^{78}$ one would most want ${ }^{79}$ to call to experience ${ }^{80}$

What do you have

5 in mind, to tear me apart ${ }^{81}$ in vain with shiverings

6 by desire loosening the knees? ...

75 Not 'feel anguish', as in Obbink's first translation (the verb is d $\alpha \dot{c} \omega$ ), or 'be hurt', as in his new one (taking now homeric $\dot{\alpha} \alpha \omega$ as the verb, which is improbable). See above, n. 59 .

$7_{6}$ I would prefer the translation 'mistress' to 'Lady' (West, who however omits Kypris) or 'Queen' (Obbink and Rayor/Lardinois [2014]). The term should be distinguished, I think, from basilea ('queen') used in the 'Brothers poem', v. 10 [6], for Hera, and in Sappho fr. 65.6 for Aphrodite, as 'queen on Cyprus' (cf. above, n. 11).

77 Obbink translates only the second $\delta \dot{\eta}$ in v. 2 ('really'). I think it is preferable to acknowledge the double $\delta \dot{\eta}$ and to translate it both in v. 1 and v. 2 as 'indeed'. Cf. above, n. 46.

78 For the missing long syllable at the beginning of v. 3, Obbink now supplies (following a suggestion of Prodi) $x \omega \dot{v}$ ('and not'), replacing the $x \alpha i$ of the editio princeps (cf. $x \alpha i$ Benelli [2015], that would also be too short). However, an alternative supplement is $x \omega \dot{\omega} c$ (= xai $\omega$ c, 'and when'), suggested by West (2014) 10, which I am adopting. Like $x \omega \nu$, it is long enough for the space, but does not introduce a further, not necessary, negation. In addition, it seems to be syntactically and semantically — and musically, as an echo of $\pi \hat{\omega} c$ - preferable. Concerning the specific semantic value of $x \hat{\omega} c$ as it could have been used in this poem, I am arguing that in Sappho, the particle $x \alpha$ í is typically not used as a conjunction ('and'), but almost ever as an emphatic adverb ('also'), and that here, it would give $\dot{\omega} c$ ('when') a further emphasis ('even', 'actually'). Instead of $\chi \dot{\omega} c$, another possible supplement is perhaps the conjunction $\theta \hat{\alpha} c$ (Aeol. = $\tilde{\varepsilon} \omega c$, 'while', attested in Alc. fr. 70.8 and fr. 206.6), giving the supplementary clause a temporal function implying purpose.

79 Obbink (2014b), West (2014), and Rayor and Lardinois (2014) translate $\theta \dot{\varepsilon} \lambda$ ol (v. 3) as 'wish(es)'. In my view, the post-homeric word $\theta \dot{\varepsilon} \lambda \omega$ (and also $\dot{\varepsilon} \theta \dot{\varepsilon} \lambda \omega$ ) in Sappho conveys rather the meaning 'I am willing to', 'I want', in distinction from the verbs she uses elsewhere for 'to wish' or 'to pray' (as e.g. äpa $\mu \alpha \iota$ in fr. 22.17). Rayor and Obbink (ch. 1, this volume) now adopt 'want' for v. 3, but, inconsistently, not for v. 9 .

8o Obbink (ch. 1, this volume) translates his restoration $\pi \dot{\alpha} \theta \alpha \underline{\alpha} \chi_{\alpha}^{\alpha} \lambda[\alpha c c \alpha l$ by 'respite from suffering'. See my arguments above (with nn. 6o-61) for the alternative restoration $\pi \dot{\alpha} \theta \eta \underline{v}$ $x \dot{\alpha} \lambda[\varepsilon \varepsilon c c \alpha$ l. With this restoration, the sense of v. 3 would be: 'even when one would most want to call upon (that person) to experience (love)'. See also above, $\mathrm{nn}$. 74-75.

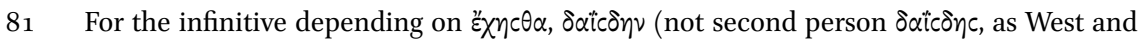
Ferrari have it), Obbink's 'to pierce' fits less well the image of the ć่ $\lambda$ or ('shiverings' [Obbink], 'tossing motions') that rather provoke a 'tearing apart'. Cf. 'to rend' in Rayor and Lardinois (2014). 


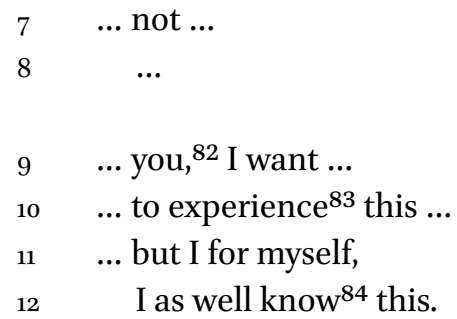

\section{What is New and not New in the New Kypris Song?}

As it were, the Kypris poem puts topics and features on display that are familiar from Sappho's hitherto extant poetry, though they are introduced to a different scenario, and new features can be detected here, too. ${ }^{85}$

To conclude this investigation, some special observations concerning the poem's terminology should be added: even in its poor state of preservation the fragment displays repetitions or variations with respect to vocabulary and stylistic patterns also to be found in other fragments. ${ }^{86}$ Among terms frequent in Sappho, the verb $\varphi \imath \lambda \varepsilon^{\prime} \omega$ (Aeol. $\varphi(\lambda \eta \mu \mu l$, 'to love'), particularly conspicuous in her poetry, ${ }^{87}$ announces the central theme of this song; yet it does so with a

82 'You' = Kypris who seems to remain the addressee (from v. 2 on) in the potential dialogue implicated in the interrogative and reflective monologue of the poetic persona evolving in this poem.

83 Another translation of $\pi \dot{\alpha} \theta \eta \nu$ would be 'to suffer', as Obbink and Rayor and Lardinois (2014) have it, as well as Ferrari ('soffrire'). However I am arguing that $\pi \dot{\alpha} \theta \eta \nu$ in v. 10 repeats the same infinitive in v. 3 and should be translated, in both instances, by 'to experience', 'to be affected' (see above, n. 61).

84 Sappho seems to be the earliest witness for the discursive intellectual term cúvoเ $\alpha \alpha$ ('to know something about someone', 'to share the knowledge about something with somebody'), that will become so prominent in Attic tragedy, oratory, and philosophy beginning with Plato, as well as in Christian theology. In the Kypris song, the goddess herself, in particular, would be the one with whom the poetic persona shares a knowledge (specifically about the vicissitudes of love).

85 This results from the evidence outlined in the first two sections of this paper.

86 Some of the terminological correspondences in fragments already known (among them also $\theta \alpha \mu \varepsilon^{\prime} \omega c$ and $\gamma o ́ v \alpha$ in the 'Tithonos poem' from a Cologne papyrus published in 2004) are noted by Obbink (2014b) 46-49. Terms that are not previously attested in Sappho (or

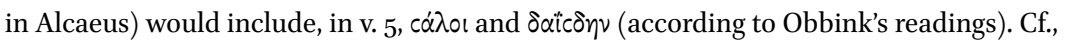
however, có $\lambda[$ in Alcaeus, fr. 73.2.

87 It is documented in eight fragments: frs. 1.23, 58.25, 59.2, 65.5, 67a.4, 88.15 and 24, 129b, 
slight suspense, only at the end of v. 2-appropriately though indirectly referring to the invocation ${ }^{88}$ of Kypris ${ }^{89}$ at the beginning of this verse. ${ }^{90}$ If Obbink's supplement is correct, the verb is used in the third-person singular, $\varphi$ i $\lambda \varepsilon i \eta$ or $\varphi(\lambda){ }^{\prime}{ }^{91}{ }^{91}$ that fits the general statement opening the poem, and not, with a

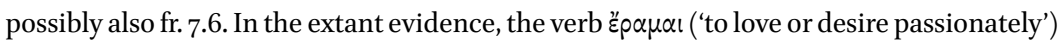
is attested much less often: fr. 16.4, fr. 49.1 (West [2014] 12 thinks that it could have appeared in the Kypris poem's v. 8).

88 This invocation, however, yields no compelling argument for the reading of the secondperson verb form $\varphi i \lambda \eta c \theta \alpha$, as West and Ferrari assume (see above), nor a need for its negation by $\mu$ ', as if for Sappho, the goddess of love could, or should, not love someone who is in love, whether a painful or a happy one.

89 As has been shown in the first section of this paper, at all three other instances in Sappho (frs. 2, 5, and 15) in which Kypris is addressed, the invocation is never placed in the opening verse but rather at the end (cf. also Kyprogenea, in fr. 22.16). Remarkably, the Kypris song also does not immediately start with an invocation of the goddess (as notably the one of Aphrodite in fr. 1.1). But even here, where Kypris is invoked relatively early, in v. 2, this functions as a coup de théâtre, since as an address to a deity, it comes completely unexpectedly after the gnomic mood-elsewhere in archaic poetry typically addressed to human partners - of the rhetorical question starting in v. 1. See also above, n. 54 .

9o The convoluted syntax (see above, $n$. 74) of the first sentence doubtlessly deserves special attention: it begins with a third-person verb and then encapsulates the address to Kypris, but, after that (according to the editor's reading) continues until its end, again with two other third-person verbs sharing with the first the common subject $\tau \iota$, as if the address had not happened. One could argue that this represents, on a formal linguistic level, the perplexing mixture between a gnomic utterance and an invocation of a goddess. Conversely, West's and Ferrari's insertion of a second-person verb at the end of v. 2 (see above), pointing to Kypris invoked at its beginning, mitigates the shocking effect of the vocative 'Kypris despoina'. On this vocative, and its peculiar combination of title and epithet, in connection with a gnomic statement, see above, nn. 54, 55, and 89 .

In his new text, Obbink (ch. 1, this volume) replaced the optative $\varphi$ i $\lambda$ ein as restoration of $\varphi(\lambda$ - by the indicative pres. $\varphi$ i $\lambda$ ncl (my suggestion in personal communication, with reference to Kühner and Gerth [1898] 258 about relative clauses not assimilated to the optative of the principal clause, when the 'Vorstellungskreise' differ). Cf. the third-person

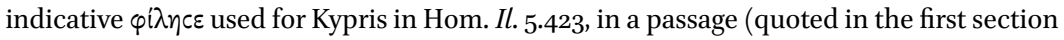
of my paper) where several terminological and stylistic correspondences to the new Kypris song are to be found (see also above, n. 46). Note that in fr. $1.23, \varphi$, $\lambda \varepsilon \varepsilon$ (and fut. $\varphi(\lambda \dot{\eta} \sigma \varepsilon \iota$ ) is used, likewise as part of a general statement (but there uttered by Aphrodite). In v. 2 of the

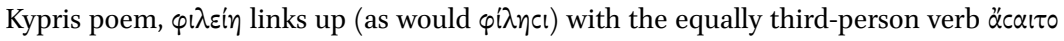
used in v. 1-issuing to the sharp semantic contrast between being disgusted and being in love (comparably expressed in fr. 1), a stylistic feature notorious from iambics, particularly Archilochus. See also above, nn. 51, 54, 59, 63, and below, n. 99 . 
negation, in the second person singular, as has been suggested by West and Ferrari. The gnomic flavor, first indicated by the indefinite personal pronoun $\tau \mathrm{Ic}$ (v. 1), being the subject of the relative clause as well, is stressed by the relative pronoun ö $\tau \tau \imath v \alpha$ ('whomsoever'), its object (v. 2). This generic relative also is quite conspicuous in Sappho, ${ }^{92}$ where it regularly points to analytical generalizations deliberately advanced by the forceful authoritative voice of the poetic persona about a typically human recurrent situation in which she herself may be included. In neuter form, the relative serves even Sappho's bold claim of an all-encompassing theory about love and beauty in her famous priamel: ${ }^{93}$

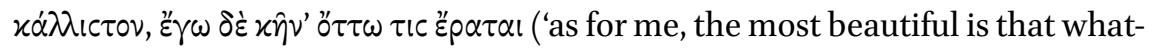
soever one loves').

Correspondingly, these items of vocabulary in the first two verses of the Kypris poem already indicate that a gnomic reflection of general applicability is developing here, and not just a particular experience restricted to women or else to the historical person of Sappho herself. This stance is further pursued in the following verse, where two other especially emphatic terms appear, equally frequent in other poems of Sappho: $\theta \dot{\varepsilon} \lambda$ ○ $\mu \alpha \dot{\alpha} \lambda \iota \tau \alpha^{94}$ ('one would want most of all'). She typically uses a combination of these two terms to designate the declared prerogative of the poetic persona, ${ }^{95}$ but here they are adapted to the generalizing aim of the statement to which they belong. The same is true for the dependent infinitive $x \dot{\alpha} \lambda \varepsilon c c \alpha$ l (Obbink's restoration in the editio princeps), 'to call', a verb by which Sappho elsewhere describes the conjuring, by the poetic voice, of something or someone missed and meant to show up, not least an object of love urged to reciprocate. ${ }^{96}$

Strikingly, all this vocabulary, together with the particularly loaded physical semantics conveyed by terms for surfeit or the disgust ensuing from it, as well

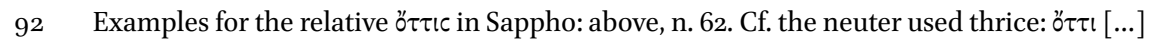
$\chi \omega ̈ \tau \tau \iota$, fr. 1.15, $\chi \omega ̈ \tau \tau \iota$, fr. 1.17. See also, for the indefinite personal pronoun $\tau \iota \mathrm{c}$ in fr. 1.18 and 19: above, n. 58 .

93 Fr. 16.3-4.

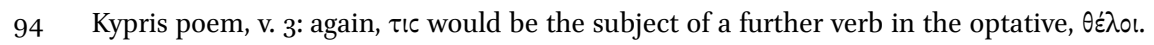
Note that the verb is repeated, in first-person present, in v. $9(\theta \dot{\varepsilon} \lambda \omega)$.

95 E.g. fr. 1.17, combining the two terms analogously to the wording of the new poem: $\mu \dot{\alpha} \lambda ı$ ıc $\alpha \alpha$ $\theta \dot{\varepsilon} \lambda \omega$.

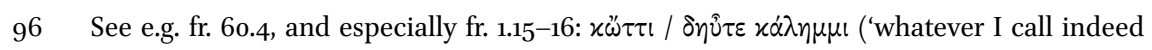
again'). Note also the combination of the relative and the particle. I am arguing that this particular emphasis on and connotation of the verb in Sappho's poetry makes the reading $x \dot{\alpha} \lambda\left[\varepsilon \in c \alpha \iota\right.$ in v. 3 of the new Kypris song more probable than $\chi^{\prime} \dot{\lambda} \lambda[\alpha c c \alpha l$, Obbink's new restoration (ch. 1, this volume). 
as for desire and the corresponding 'loosening' (or 'maddening'), ${ }^{97}$ also occur in the famous so-called 'Hymn to Aphrodite' (fragment 1), where such a terminology is equally part of an intimate communication with the goddess. But there, it is the Olympian Aphrodite herself who pronounces a general statement about the discomforting vicissitudes of love. ${ }^{98}$ Yet the poetic persona-although she enters in a face-to-face dialogue with the goddess (the 'fellow-fighter'99 she again calls upon at the end) as if she were an epic hero or heroine, and imagines herself as almost her equal — is left with her mortal suffering in the present and to some extent in the past, though with hopes for the future, perhaps even for a superhuman telos in a blissful afterlife. ${ }^{100}$ The 'Kypris Poem' is no less dramatically structured and coherent, but here, conversely, it is the suffering human who is in charge of gnomic thinking, and not the divine addressee, the all-tooanthropomorphic epic Kypris, the goddess who may be a cultic protector of seafaring, but in any case has the tendency, in ancient Greek cultural imagination, to lead women, or else men, to unrestricted sexual behavior, in her quality as a powerful despoina marked by irresponsible thoughts and unmitigated arbitrariness of action.

As far as we can judge from the mutilated residues of the text, what seems to dominate here is actually less the goddess but rather something specifically human:101 the need to analyse and reflect on what happens if one is exposed to love and to its capricious and deceptive goddess who did not (or no longer) simultaneously expose to love whomever one loves. In fact, this accounts for every human, female and male alike. And this could explain why among the mortals in this song, at least in its extant parts, neither the indefinite thirdperson agent with whom it starts is gendered, nor the elusive love object that

97 Nausea: here v. 1, cf. fr. 1.3; desire: here (possibly) v. 6, cf. fr. 1.27; loosening: here (possibly) v. $6(\lambda \dot{v}\{\iota\} c \alpha \nu \tau \iota)$, cf. fr. 1.25. See also West (2014) 11 who suggests the alternative reading

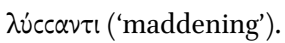

98 Articulated in the penultimate stanza, fr. 1.21-24, which is, surprisingly enough, often interpreted in scholarship as a consolation for the suffering lover (but note the conspicuous absence of personal pronouns there, a fact rarely respected in translations and interpretations).

99 Fr. 1.28: cú $\mu \alpha \chi 0 c$, a noun attested before Sappho only in Archilochus, fr. 108.1 (for Hephaestus, invoked as 'fellow-fighter' of the male poet in his capacity as warrior).

100 See above, n. 11.

101 In this respect, there are some analogies with another famous poem, equally about unrequited love, but especially describing the physical effects of this painful experience, fr. 31, where, however, the goddess of love is absent (pace D'Angour [2006] and [2013], see above, n. 32), as is, strikingly, any explicit word terminologically pointing to love. 
subsequently emerges in his wake, but exclusively the I of the poetic persona, whose stubborn will, declared in front of the goddess, ${ }^{102}$ ultimately takes over.

Thus the Kypris song seems to deploy a poetical theory of love en miniature. This is conveyed by means of a conversational gesture, in the manner of gnomic statements in iambic or elegiac poetry, however not addressed to a human companion, but to the goddess of love, who is disclosed as addressee in the second verse, making it clear that in love affairs she always lurks in the background and sometimes, at least for her favorites, also in the foreground. From an almost clinical report based on general experience and individual expertise, a reflection evolves about what it means to love whilst not being loved. This analysis is offered (in the form of two questions) to Aphrodite, the alter ego of the poetic persona in Sappho's work, as something to think about. Yet she is invoked here, more specifically, not only as Kypris but also as despoina, that is, with both her most ancient title and an epithet never attested before Sappho for a goddess - as if Sappho wanted to emphasize her own poetical skill with which she underscores the closeness of this goddess to human power, but less to human insight and reason.

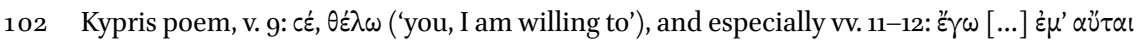
$[\ldots]$ cóvoเ $\delta \alpha$ (note here the particularly bold tripling of the I, which is apparently only now gendered as female, in v. 11: $\left.\dot{\varepsilon} \mu^{\prime} \alpha \tilde{u}^{\prime} \tau \alpha \mathrm{l}\right)$. This emphatic stress on the first person as subject in control of its agency and simultaneously object of self-reflection in the third stanza would be weakened, I think, if $\varepsilon^{\prime} \gamma \omega$ already appears in the second stanza, as Ferrari (2014) 13-14 conjectured for v. 6. Note that the expression $\varepsilon^{\prime} \mu^{\prime} \alpha v^{\prime} \tau \alpha$ is also to be found in fr. 31.16 (after a first, equally quite late gendering of the I, in fr. 31.14), though connected there not to knowledge but to a physical feeling, which the female I 'seems' ( $\varphi \alpha^{\prime}(v \circ \mu$ ') to perceive as not far from death. 